Brit. F. vener. Dis. (1975) 51, 3

\title{
Resolution on the control of sexually-transmitted diseases
}

\author{
COUNCIL OF EUROPE \\ COMMITTEE OF MINISTERS
}

\begin{abstract}
A Working Party on Venereal Diseases ${ }^{\star}$ was appointed by the European Public Health Committee in 1972. As one of the background documents for the Working Party a report was prepared by Dr. Thorstein Guthe (Guthe, 1974). As a result of its work the Working Party presented to the European Public Health
\end{abstract}

Committee a draft resolution on the control of sexually-transmitted diseases which, after approval by the above Committee, was adopted by the Committee of Ministers on February 27, 1974, at the 229th meeting of the Ministers' Deputies.

\section{RESOLUTION (74) 5}

ON

\section{The Control of Sexually-Transmitted Diseases (STD)}

The Committee of Ministers,

Considering that the aim of the Council of Europe is to achieve a greater unity between its Members and that this aim may be pursued, inter alia, by the harmonisation and adoption of common regulations in the social field and particularly in regard to public health aspects;

Considering that the "venereal" and other sexuallytransmitted diseases (STD) have now become a most frequent serious and costly public health problem, and sometimes show epidemic spread within and between countries and appear to be mainly attributable to:

-demographic changes, increased population mobility, social and economic progress and particularly the development of an industrial civilisation;

*The members of the Working Party, who each produced background documents, were: A. Betz (Chairman: Luxembourg); C. S. Nicol (Rapporteur: United Kingdom); T. Guthe (Consultant: Norway); G. Aagaard Olsen (Denmark); P. Hertoft (Denmark); G. Caletti (Italy); L. Juhlin (WHO Representative: Sweden); O. Laurencic (Austria); Mrs. C. Idoux (France) -altered behavioural and social attitudes resulting from the continuing effects of these many developments on human relationships in adolescent and adult groups;

- the neglect, in some countries, of sex and health education, notably among the young;

- the often asymptomatic nature of these infections, and a false sense of security due to the effectiveness of modern drug therapy and new contraceptive methods,

all of which, in a rapidly changing environment, tend to enhance casual human encounters, promote sexual relationships, and facilitate the acquisition of diseases transmitted in this way;

Considering the need for sex and health education, medical, epidemiological, psycho-social, and other services, as well as for professional training and research;

Considering that national services for STD control are not yet fully supported by rules and regulations, that available facilities are sometimes incompletely utilised, and that co-operation between member states has been limited; 
Considering also that available methods in the public health control of sexually-transmitted diseases are capable of reducing the problem whenever medical, administrative, and social measures are intensified,

I. Recommends that the governments of member states take into account in their national legislation, regulations and procedures, the definitions, principles, and practices outlined in Appendices $A, B$, and $C$ to this resolution, co-ordinating the action in their health programme to harmonise with the technical policies of the World Health Organisation;
II. Invites the governments of member states to inform the Secretary General of the Council of Europe every 5 years of the action taken by them in respect of the present resolution.

\section{Reference}

GutHE, T. (1974) "Sexually Transmitted Diseases (STD): Scope and Control Measures". Council of Europe European Public Health Committee, Strasbourg.

\section{Appendix A}

With a view to promoting progress in the control of STD in member states, the following principles and practices should be given the fullest effect:

\section{(1) Harmonisation of rules and regulations concerning communicable diseases with a view to achieving more effective control of STD in each country and internationlly, with particular reference to:}

$a$. Numerical reporting to health authorities by doctors, clinics, health centres, hospitals, and laboratories of diagnosed new cases of STD enabling health administrations to improve statistical data, to evaluate trends better and to appraise epidemiological and other control measures more effectively;

$b$. Definition of terms and nomenclatures in the reporting of STD in order to ameliorate the quality of the data obtained;

c. Use of an agreed uniform classification of STD to attain more meaningful inter-country comparison of the occurrence of STD, assessment of long-term trends and evaluation of the measures undertaken;

$d$. Gradual introduction and use of computerised data processing aiming at the periodic provision of up-to-date information on STD occurrence as a basis for their national and for inter-European surveillance.

(A model defining the terms, nomenclature and classification of STD to be used in the first phase of the programme as a periodic return to the health authorities by doctors and medical institutions is given in Appendix $B$. A model laboratory form enabling assessment of workloads in official laboratories concerned with STD examinations is outlined in Appendix C.)

(2) Improvement of case-finding to interrupt transmission, facilitate prevention and treatment, and obviate complications of STD by:

a. A system for obligatory or voluntary tracing of contacts of diagnosed cases of STD-notably gonorrhoea and early syphilis - through social workers or equivalent personnel provided by health authorities to doctors and medical institutions; the maintenance of a confidential data system concerning habitual infectors as a basis for co-ordinated public health and social measures;

b. Systematic inclusion of sero-testing for syphilis in pre-marital and pre-natal examinations; promotion of similar procedures as well as examinations for gonococcal and other STD infections in family planning, cervical cytology and other clinics, and in gynaecological outpatients; screening of populations recognised to be at particular risk of infection, including seafarers and armed forces;

c. Maintenance of professional confidentiality concerning diagnosis, treatment and notification of contact details by all health personnel and medical institutions to health administrations within and between European countries, using medical administrative channels and preferably standard forms, thus improving present collaboration.

(3) Provision without cost to patients of diagnostic, therapeutic, and other services to ensure early diagnosis and treatment of STD by:

a. A system of free diagnosis and medical care provided by the state;

$b$. Inclusion of STD in the coverage of health and social security schemes, if not yet done, and in reciprocal agreements between European countries;

c. Extension - when such agreements are not yet established - of the principles of the international Brussels Agreement concerning seafarers to cover free drugs, ambulatory treatment, hospitalisation, laboratory and other services regardless of nationality, for international travellers, migrants and other itinerant population groups. 
(4) Amelioration of diagnostic, therapeutic, and social services to improve patient management and interorganisational collaboration by:

a. Recognition of a competent laboratory to act as a national reference laboratory in each European country to check and furnish antigens to other laboratories undertaking serological tests for treponematoses; to assess annually serological test performance in co-operation with other laboratories so as to promote comparability of results; to assist peripheral laboratories to upgrade cultural diagnostic techniques for gonorrhoea as a requisite for better diagnosis (in addition to stained smears);

$b$. Promotion of inter-European collaboration so as to standardise antigens, tests and records in harmony with the technical policies of WHO; participation in the activities of international reference centres to achieve greater uniformity in the methods used for serological test standardisation in syphilis and for antibiotic sensitivity pattern determination in gonococci;

c. Intensification of surveillance and control examinations after STD treatment in order to improve the possibilities for diagnosing multiple or recurrent infections;

$d$. Provision of adequate equipment and supplies aiming at the introduction of modern laboratory methods, including automated techniques to facilitate screening of population groups;

$e$. Upgrading of clinic premises for STD services at medical institutions to increase their attractiveness to patients, providing adequate waiting space, assuring separate male and female facilities, sympathetic reception of patients, support through social workers, family planning referral, when indicated, and other forms of aid; integration of the STD activities of medical institutions with those of other disciplines and institutions (e.g. referral of patients), of local health authorities (e.g. contact tracing), of health education agencies, and teaching activities; reporting of statistics and budget requirements to health authorities - all part of the additional functions of the medical institutions concerned; furthermore, the promotion of main centres to assist in the national and international promotion of STD control.

(5) Upgrading and strengthening of professional training to encourage recruitment of staff to meet rising needs by:

$a$. Intensification of teaching and hospital training in STD control and allied subjects in the medical curriculum of universities at graduate and postgraduate levels, including refresher courses, in order to furnish better qualified physicians and subsequently a sufficient number of specialists in the STD discipline; $b$. Improvement of post-basic training of nurses to staff clinics by the provision of a suitable syllabus including practical training;

c. Training of social workers and of related paramedical personnel, notably in counselling and in epidemiological contact action so as to improve the services available to STD clinics, health centres, hospitals and medical practitioners;

d. Provision of ancillary staff, such as receptionists and secretaries, to relieve professionally trained staff-members, and of coding clerks at major STD centres in the gradual adaptation of reporting systems to computerised data processing.

(6) Increased medical research co-operation in Europe to provide better control of STD by:

a. Establishment of co-operative investigative groups concerned inter alia with defining:

$i$. the condition in which epidemiological and mass treatment of STDs might be useful and acceptable; the clinical, epidemiological, and antibiotic resistance patterns in gonorrhoea; the problem of multiple infections and disabling complications in males and females, including sterility; the aetiology, diagnostic criteria, and apparent uneven distribution of reporting in Europe of non-gonococcal genital infections, their nature, complications, and therapy;

ii. elucidating the possible association of genital herpes with the occurrence of cervical cancer;

$b$. Stimulation of investigations in "frontier areas of knowledge" where a "breakthrough" might lead to applied methods which could be essential in more effective control of STD, notably:

$i$. search for "early warning tests" which, in syphilis, could permit diagnosis in the incubation period and, in gonorrhoea, better identification of the disease in clinically asymptomatic infectors, notably females;

ii. study of growth factors and antigenic structures of the causative agents of syphilis and gonorrhoea, pursuing present leads to possible vaccine development;

iii. assessment of effectiveness, acceptability, and possible epidemiological impact of contraceptives embodying anticonceptional and anti-infective ingredients, e.g. condoms and vaginal preparations;

c. Provision of grants-in-aid by national and international (governmental and non-governmental) agencies and of research fellowships and travel grants for STD research purposes.

(7) Newer approaches to health education and psychosocial care for control and prevention of STD by:

a. Introduction in schools of programmes allowing children to acquire progressive knowledge of human 
sexuality in its biological, behavioural, and other aspects, and information in STD in association with discussions of behavioural relationships which depend on varying cultural and social patterns in different countries; integration of parent instruction in such educational programmes so as to avoid disapproval and obtain co-operation;

b. Financing by governments or state-assisted agencies of health education programmes using modern mass media techniques, lectures, debates, group discussions, and various audio-visual aids, aiming particularly at young people and at other special STD risk groups, such as tourists, migrants, seafarers, and members of the armed forces; promotion by these agencies of teaching activities for information disseminators, such as teaching staff, medical and nursing personnel, social and welfare workers;

c. Active efforts by governments, health authorities, and institutions:

$i$. to promote social prevention of STD by intensifying the training of social workers and providing suitably qualified personnel for psychosocial care and guidance, notably of STD patients with recurrent infections, aiming at re-alignment of their mental and social attitudes so as to regain a balanced relationship with their modern environments, thus preventing exposure risks of repeated STD infections in the community;

ii. to improve co-operation between the psychosocial care and referral services in the community and the agencies and organisations concerned with training, rehabilitation, job placement, recreation, housing, family planning, and assistance as well as other social aid and security programmes so as to facilitate a progressive integration into new environments of young people and other groups at risk, STD being often associated with other conditions which also result from social pressures, such as drug addiction and alcomania;

$d$. Encouragement of pilot projects in regions of northern and southern Europe with different cultural patterns:

$i$. providing medical training programmes, casefinding and psycho-social services, integrated in a well-equipped national or regional centre-aiming at the prevention of STD and focusing on the improvement of technical services for diagnosis and treatment and on health education of the society as a whole, notably the family, the school, and industry;

ii. investigating the usefulness of self-sampling techniques in the diagnosis of female gonorrhoea, encouraging self-motivation for this purpose through health education in STD and/or family planning clinics; also assessing in a socio-psychiatric project in high STD risk groups the possible influence of health education on social conditions and behavioural patterns, the outcome of such projects being of interest to all member states;

$e$. Promotion by grants, fellowships, and other forms of support through regional, national, international, governmental and non-governmental organisations of basic and applied research by means of national and international European groups concerned with:

$i$. psycho-social aspects and behavioural patterns conducive to risks of acquiring STD;

ii. the effectiveness of health education programmes in relation to individuals and groups in the social prevention of STD.

(8) Progressive development of STD control through its effective integration with communicable diseases and other health services by:

a. Maintaining a full or part-time post to advise the central and/or regional health administration on STD services, to collate data and evaluate morbidity trends; review the activities and needs of epidemiological, medical, social and other supporting services, with a view to the improvement of the available facilities and their functioning;

$b$. Upgrading of clinics to provide diagnostic, therapeutic, and follow-up services on a regional basis, in out-patient departments in main hospitals of urban areas and maintenance of reciprocal contact with other hospital services where early or late cases of STD are likely to be encountered;

c. Working closely with consultants, medical officers, and health administrations responsible for other government health programmes; with regional and local health officers and practitioners; maintaining liaison with medical institutions, local and central reference laboratories, the associations of the medical profession, and with voluntary organisations;

$d$. Assuring adequate budgets at central, regional, and local levels from governmental and other sources to support the control of STD and other communicable diseases and as far as possible to plan well in advance relevant budgets to provide for necessary expansion.

(9) Long-term assessment of the medical, social, and economic consequences of STD and the progress made in their control by keeping under surveillance national trends of STD incidence and control and their inter-country spread in Europe. 


\section{Primary}

Secondary

Early latent

\section{Cardiovascular}

Nervous system

All other latent and late stages

\section{Congenital}

\section{Congenital}

\author{
Newborn \\ Pre- and post- \\ pubertal \\ Lower genito- \\ urinary tract \\ infection \\ Mouth, throat \\ and eye \\ infection \\ Upper genital \\ tract compli- \\ cation \\ Systemic \\ complications
}

\section{Definitions}

\section{A. Syphilis}

: Genital/extragenital chancre with regional lymphadenitis, etc.

: General adenopathy, cutaneous rash, mucous membrane involvement, alopecia, iritis, etc.

: Seroreactive (confirmed by specific tests), spinal fluid non-reactive, clinically symptomless syphilis, estimated to be of less than 2 years' duration.

: Aortitis, aneurysm, coronary ostial stenosis. For recording of simultaneous nervous system involvement, see footnote 2 to table.

: Meningitis, cranial nerve and vascular involvement, tabes dorsalis, general paralysis (syphilitic meningo-encephalitis), etc.

: a. Clinically asymptomatic, seroreactive and spinal fluid non-reactive syphilis estimated to be of more than 2 years' duration.

$b$. Late "benign" syphilis, gumma of integuments or deeper tissues or involvement of organ systems.

: (patient under 2 years) Coryza, cutaneous rash, mucous and visceral involvement, osteochondritis, etc.

: (patient over 2 years) Rhagades, frontal bosses, sabre tibia, dental deformities, interstitial keratitis, deafness, saddle nose, systemic involvement, etc.

\section{B. Gonorrhoea}

: Ophthalmia neonatorum and/or infection of ano-genital orifices.

: Physician's judgement determines pre- or post-pubertal infection.

: Urethritis, tysonitis, cervicitis, bartholinitis, vulvitis, proctitis, etc.

: Stomatitis, pharyngitis, tonsillitis, conjunctivitis, etc.

: Salpingitis and other pelvic involvement, prostatitis, epididymitis, cowperitis, etc.

: Gonococcaemia, septic dermatitis, arthritis, tenosynovitis, anterior uveitis, endocarditis, myositis, meningitis, etc.

\section{Further genital infections}

Chancroid

Lymphogranuloma venereum

Granuloma inguinale

Non-gonococcal genital infections

Non-gonococcal genital infections with systemic complications
: Smear or culture identification of $H$. ducreyi and/or positive intradermal test (ItôReenstierna).

: Identification of Chlamydia (group A), by tissue culture, intradermal test (Frei), or antibody complement-fixation test.

: Identification of Donovan bodies from lesions.

: Exclusion of gonorrhoea (Trichomonas cases included here).

: Variants of the urethro-conjunctivo-synovial syndrome (Reiter's disease).

\section{Other STD or related diseases treated}

Candidiasis, genital scabies, pediculosis pubis, genital herpes, condylomata acuminata, genital molluscum contagiosum; related diseases include treponematoses other than syphilis.

\section{E. Other conditions not requiring treatment within a specialised STD centre}

Includes other genital or non-genital conditions needing referral to specialised clinics, non-genital conditions not needing treatment, and cases where no abnormalities were found. 
A P P E N D I X B

Suggested model for a reporting form for sexually transmitted diseases (STD)

No. of persons attending for the
first time during the indicated
period with the diagnoses below
$\ldots \ldots \ldots \ldots$

\begin{tabular}{ll}
\hline Quarter ending March & 197. \\
Quarter ending June & 197. \\
Quarter ending September 197. \\
Quarter ending December 197.
\end{tabular}

Number of new cases ${ }^{1}$ reported quarterly for statistical purposes by doctors, medical institutions (clinics, health centres, hospitals etc.)

to health authorities in member states of the Council of Furope

\begin{tabular}{|c|c|c|c|c|c|c|c|c|}
\hline \multirow{3}{*}{$\begin{array}{c}\text { Diagnostic groups } \\
\text { (for definitions of terms } \\
\text { see overleaf) }\end{array}$} & \multicolumn{2}{|c|}{ TO T A L } & \multicolumn{2}{|c|}{$M A L E S$} & \multicolumn{4}{|c|}{ F E M A I. E S } \\
\hline & \multirow{2}{*}{$\begin{array}{l}\text { Period } \\
\text { this } \\
\text { year }\end{array}$} & \multirow{2}{*}{$\begin{array}{l}\text { Same } \\
\text { period } \\
\text { last } \\
\text { ycar }\end{array}$} & \multirow{2}{*}{$\begin{array}{l}\text { Pcriod } \\
\text { this } \\
\text { year }\end{array}$} & \multirow{2}{*}{$\begin{array}{l}\text { Same } \\
\text { period } \\
\text { last } \\
\text { year }\end{array}$} & \multicolumn{2}{|c|}{$\begin{array}{l}\text { Period } \\
\text { this year }\end{array}$} & \multicolumn{2}{|c|}{$\begin{array}{l}\text { Same period } \\
\text { last year }\end{array}$} \\
\hline & & & & & $\begin{array}{c}\text { Non- } \\
\text { pregnant }\end{array}$ & Pregnant & $\begin{array}{c}\text { Non- } \\
\text { pregnant }\end{array}$ & Pregnant \\
\hline $\begin{array}{l}\text { A. Syphilis } \\
\text { Primary } \\
\text { Secondary } \\
\text { Early latent (less than two years) } \\
\text { Cardio-vascular } \\
\text { Nervous system } \\
\text { All other late and latent stages } \\
\text { Congenital (under two years of age) } \\
\text { Congenital (over two years of age) }\end{array}$ & & & & & & & & \\
\hline \multicolumn{9}{|l|}{ Total under $A$} \\
\hline \multicolumn{9}{|l|}{$\begin{array}{l}\text { B. Gonorrhoea } \\
\text { Newborn } \\
\text { Pre-pubertal } \\
\text { Post-pubertal } \\
\text { - with lower genito-urinary tract } \\
\text { infection } \\
\text { - with mouth and throat infection } \\
\text { - with eyc infection } \\
\text { - with upper genital tract } \\
\text { complications } \\
\text { - with systemic complications }\end{array}$} \\
\hline Total under B & & & & & & & . & \\
\hline \multicolumn{9}{|l|}{$\begin{array}{l}\text { C. Further genital infections } \\
\text { Chancroid } \\
\text { Lymphogranuloma venereum } \\
\text { Granuloma inguinale } \\
\text { Non-gonococcal genital infections } \\
\text { Non-gonococcal genital infections } \\
\text { with systemic complications }\end{array}$} \\
\hline \multicolumn{9}{|l|}{ Total under $C$} \\
\hline \multicolumn{9}{|l|}{$\begin{array}{l}\text { D. Other STD or related di seases } \\
\text { treated }\end{array}$} \\
\hline \multicolumn{9}{|l|}{ Total under D } \\
\hline \multicolumn{9}{|l|}{ GRAND TOTALS A, B, C, D } \\
\hline $\begin{array}{l}\text { E. Other conditions not requiring } \\
\text { treatment within a specialised } \\
\text { STD Centre }\end{array}$ & & & & & & & & \\
\hline
\end{tabular}

1. Seen for the first time for the present condition and reported for the first time by a doctor or clinic.

2 . In order to avoid duplication, patients with cardio-vascular syphilis who are also suffering from syphilis of the nervous and/or other systems are recorded as suffering from cardio-vascular syphilis alone. 
A P P ENDIX C

Name and address of national laboratory

\begin{tabular}{ll}
\hline Quarter ending March & 197. \\
Quarter ending June & 197. \\
Quarter ending September & 197. \\
Quarter ending Eecember & 197. \\
\hline
\end{tabular}

\section{Suggested model for a reporting form for} sexually transmitted diseases (STD)

Examinations carried out in national laboratories, reported to health authorities in member states of the Council of Furope

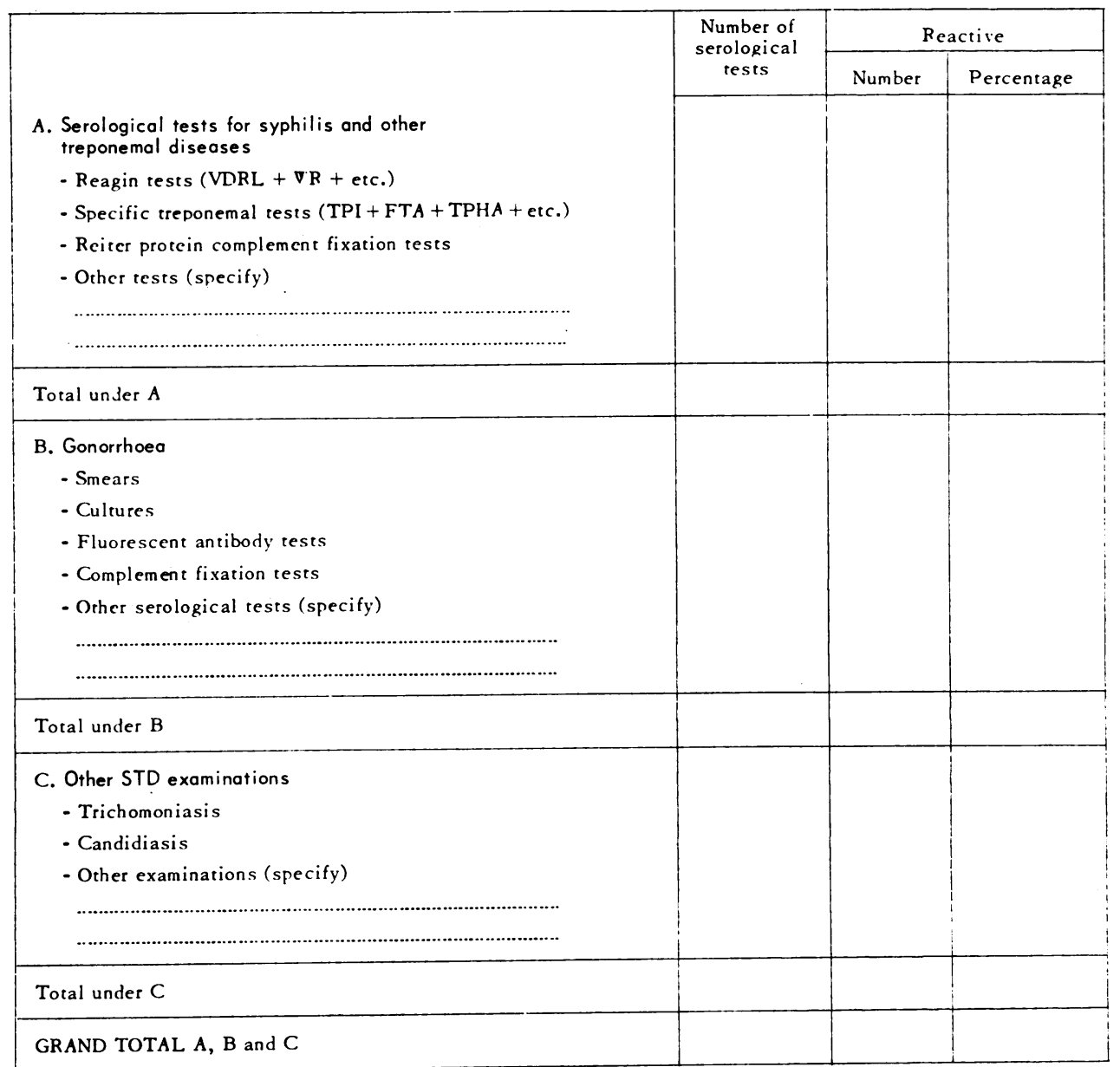

N.B. : The purpose of this form is to indicate the workload of the laboratory concerning STD examinations. The total number of each type of test undertaken in each category is totalled and inserted 